\title{
GESTÃO INTEGRADA E ADAPTATIVA DA ÁGUA: A GOVERNANÇA DA BACIA DO ALTO TIETÊ EM FACE DA ESCASSEZ HÍDRICA
}

\author{
Amauri POLLACHI ${ }^{1}$
}

RESUMO: As incertezas associadas à mudança climática, de certa forma, induzem que a governança das águas estruturada conforme a Gestáo Integrada de Recursos Hídricos (GIRH) associe-se à Gestão Adaptativa (GA), promovendo maior participação social, flexibilidade e adaptabilidade. Entidades regionais de gestão das águas, os Comitês de Bacia têm papel fundamental nesse processo, pois reúnem parcela representativa dos atores governamentais, de usuários e da sociedade civil, interessados por ou relacionados com governança das águas. A escassez hídrica de 2013-2015 afetou severamente o território da Macrometrópole Paulista, no qual se situa a Bacia Hidrográfica do Alto Tietê, colocando à prova a governança implantada no estado de São Paulo. O objetivo deste artigo é apresentar, em face desse evento crítico, a atuação do Comitê da Bacia do Alto Tietê quanto à participação, à integração e ao conhecimento, bem como apontar possíveis aspectos de evolução para uma gestão integrada e adaptativa de recursos hídricos.

PALAVRAS-CHAVE: governança da água; gestão adaptativa; comitê da bacia hidrográfica do alto tietê; escassez hídrica

\section{INTEGRATED AND ADAPTIVE WATER MANAGEMENT: ALTO TIETE WATER BASIN GOVERNANCE IN THE FACE OF THE WATER SCARCITY}

ABSTRACT: The uncertainties related to climate change induce the governance of water structured according to the Integrated Water Resources Management (IWRM) to associate

\footnotetext{
1 Universidade Federal do ABC (UFABC), Santo André - SP - Brasil. Mestre em Planejamento e Gestão do Território. Universidade de São Paulo (USP), São Paulo - SP - Brasil. Graduado em Engenharia Mecânica e História. É pesquisador no Projeto Temático MacroAmb, financiado pela FAPESP. ORCID: https://orcid.org/00000003-0103-4707. apollachi@gmail.com.
} 
with Adaptive Management (AM), improving social participation, flexibility, and adaptability. Regional water management authorities, as the Water Basin Committees, play a fundamental role in this process, as they gather a representative portion of government actors, users, and civil society interested in or affected by water governance. The water scarcity of 2013-2015 severely affected the territory of the São Paulo Macrometropolis, in which the Alto Tietê Hydrographic Basin is located, testing the water governance implemented in the State of São Paulo. The purpose of this article is to present and assess, in the context of this critical event, the performance of the Alto Tietê Water Basin Committee regarding its participation, integration and knowledge, and point possible issues for improvement towards an integrated and adaptive water resources management.

KEYWORDS: water governance; adaptive management; alto tiete water basin committee; water scarcity

\section{Introdução}

De modo geral, a Gestão Integrada de Recursos Hídricos (GIRH) pressupóe a adoção, na escala da bacia hidrográfica, de princípios institucionais de interação de gestão, participação da sociedade civil, valoração econômica da água e integração com outras políticas públicas relacionadas.

Para lidar com os desafios associados à distribuição de água condizente com a manutenção das atividades humanas e dos seres vivos, Pahl-Wostl et al. (2005, p.4) defendem que a GIRH, deve ser capaz de "responder às mudanças no ambiente natural e social e antecipar-se às incertezas associadas a essas mudanças.”. Os interesses múltiplos e às vezes contraditórios sobre a água têm mostrado que "decisões sobre alocação e distribuição não podem ser sustentáveis se fragmentadas pela concorrência através de escalas e setores." (ENGLE et al., 2011, p.1).

Essas questôes da gestão das águas encontram respostas na Gestão Adaptativa (GA), que está assentada sobre teorias de resiliência e envolvida com a gestão de incertezas por meio da experimentação formal e da aprendizagem baseada em processos sociais. Segundo Engle et al. (2011), dada a ampliação de incertezas devido à mudança climática e também pelas condiçóes socioeconômicas, a associação da GIRH com a GA permite uma conjugação de teoria e prática com potencial combinação de diferentes instituiçóes e mecanismos para: (i) o incremento de eficácia; a participação e a democratização do público em geral e das partes interessadas; a ampliação do conhecimento por diferentes formas; e, a promoção de flexibilidade e adaptabilidade. 
No Brasil e no estado de São Paulo, a governança das águas está claramente apoiada sobre os princípios basilares da GIRH de descentralização, participação, integração e reconhecimento da água como um bem público e dotado de valor econômico. Nessa concepção, a bacia hidrográfica é a unidade de planejamento e gestão de recursos hídricos em que os Comitês de Bacia Hidrográfica, com a participação do Poder Público, dos usuários e da sociedade civil, cumprem um papel fundamental na GIRH e constituem-se em espaços para a evolução da governança das águas rumo a uma gestão adaptativa e integrada, pois facilita interaçóes de múltiplos atores envolvidos (JACOBI et al., 2009).

A grave escassez hídrica de 2013-2015, que afetou severamente as bacias hidrográficas inseridas na Macrometrópole Paulista, foi uma oportunidade para avaliar a aplicação da governança da água nesse território. Para Barbosa, Alam e Mushtaq (2016, p.11), a implementação e a aplicação eficaz das políticas de GIRH no estado de São Paulo enfrentavam desafios em quatro dimensóes: institucional e governança; política; financeira; e, técnica, uma vez que "as partes interessadas acreditam que os desafios das dimensôes de governança, institucional e política são mais importantes que os técnicos e financeiros.”.

Entretanto, durante a grave escassez hídrica de 2013-2015, o sistema paulista mostrou, na prática, distanciamento de seus princípios basilares a dificultar, sobremaneira, a sua evolução rumo a uma gestão integrada e adaptativa de recursos hídricos.

No presente artigo, utilizou-se uma metodologia em que, primeiramente, é apresentada uma breve revisão bibliográfica sobre a Gestão Integrada de Recursos Hídricos e a Gestão Adaptativa, bem como sobre a política e a gestão dos recursos hídricos instituída nas escalas nacional e paulista.

A seguir, o foco concentra-se em um estudo de caso sobre uma das instâncias que compóem a governança das águas de São Paulo, o Comitê da Bacia Hidrográfica do Alto Tietê (CBH-AT), no que diz respeito à participação, integração e conhecimento durante o evento crítico de 2013-2015. A pesquisa utilizou-se de documentos (atas, deliberação, decretos, etc.) associados à atuação do CBH-AT e dos protagonistas da governança hídrica nesse período.

Por fim, apresentam-se alguns aspectos perceptíveis de evolução na governança do CBH-AT, que mostram potencial para, futuramente, compor o pavimento em direção a uma gestão integrada e adaptativa. 


\section{A governança da água segundo o modelo da gestão integrada de recursos hídricos}

No último quarto do século XX, o modelo de administração de recursos hídricos até então praticado, caracterizado por uma rigidez nos princípios de comando e controle e nas práticas de centralização e de decisóes verticais, não mais respondia à inegável constatação da água como recurso finito, vulnerável e submetido a conflitos e interesses de diferentes atores sociais. Em substituição a essas práticas, criou-se a da Gestão Integrada de Recursos Hídricos (GIRH), um modelo de gestáo capaz de reconhecer o ambiente e a escala, promover a transição em direção à sustentabilidade no que diz respeito aos diversos usos da água e mediar os conflitos entre as partes interessadas, superando o modelo prévio que se julga hoje como anacrônico.

Kramer e Pahl-Wostl (2014) situam o início da formulação da GIRH na década de 1950, e destacam que "no final dos anos 1980, o conceito de GIRH foi bem estabelecido em publicaçóes científicas e em reunióes de profissionais dedicados à política da água, sem ainda figurar como modelo dominante para discutir os assuntos relativos à água." (CONCA, 2006 apud KRAMER; PAHLWOSTL, 2014, p.1).

A Conferência Internacional sobre Água e Meio Ambiente da Organização das Naçóes Unidas, em 1992, em Dublin, inaugurou o consenso das naçóes para o exercício da eficiente gestáo de recursos hídricos sob o princípio de que “a escassez e o mau uso da água doce são fatores de grande e crescente risco ao desenvolvimento sustentável e à proteção do meio ambiente" (ONU, 1992). Benson, Gain e Rouillard (2015) descrevem que o conceito de GIRH foi reafirmado em conferências da Organização das Naçóes Unidas (ONU) e amplamente adotado a partir dos anos 1990 por organismos internacionais de fomento, como o Banco Mundial, e por políticas internacionais, como as da União Europeia, disseminando-se sua definiçãa como:

Um processo que promove o desenvolvimento e a gestão coordenados da água, da terra e dos recursos relacionados, a fim de maximizar o resultante bem-estar econômico e social de forma equitativa, sem comprometer a sustentabilidade dos ecossistemas vitais. (GWP, 2018).

De modo geral, GIRH pressupóe a adoção, na escala da bacia hidrográfica, de princípios institucionais de interação de gestão, participação da sociedade civil, valoração econômica da água e integração com outras políticas públicas 
relacionadas. A GIRH é percebida como "o modo de integrar todas as questóes ambientais, sociais e econômicas relevantes, para refletir a realidade biofísica e integrar todas as partes interessadas, com base no mais recente conhecimento." (GUPTA; PAHL-WOSTL; ZONDERVAN, 2013, p.575). Contudo, observa-se que a sua aplicação em escala planetária tem sido lenta e, de certo modo, muito difícil, tendo em vista a "limitada capacidade de muitos países de implementar até a mais simples legislação.” (PAHL-WOSTL et al., 2012, p.25).

Não obstante a Assembleia Geral da ONU, em 2010, ter aprovado a Resolução 64/292 que declara o "direito à água potável e segura e ao saneamento como direito humano essencial para o gozo pleno da vida e de todos os direitos humanos." (ASAMBLEA GENERAL DE LAS NACIONES UNIDAS, 2010), avançam iniciativas contraditórias. Brenner (2018) identifica a transformação da água em bem transacional no contexto regulatório da neoliberalização, por meio de processos de comoditizaçáo. Nessa vertente, em dezembro de 2020 foi lançada a cotização da água no mercado de futuros de Wall Street (ALVAREZ, 2020), colocando em risco a garantia de acesso universal a um bem comum essencial, especialmente em cenários de mudanças climáticas acompanhadas de eventos cada vez mais frequentes e graves de escassez hídrica.

\section{A gestão adaptativa e integrada}

A governança de recursos hídricos, desde a escala global até a local, está intrinsecamente conectada à governança ambiental, esta, por sua vez, influenciada pela intervenção direta das açóes humanas que contribuem para a crise climática planetária.

A interligação dos processos hidrológicos e de gestão dos recursos hídricos tem sido reconhecida nas escalas local e de bacias hidrográficas. A Gestão Integrada de Recursos Hídricos - GIRH, como o nome sugere, é um paradigma de gestão ambiental, reconhecendo explicitamente a natureza complexa do sistema de água e suas interdependências, simultaneamente procurando evitar imprevistas e indesejáveis consequências geradas por intervenções isoladas de gestão. (PAHL-WOSTL et al., 2013, p.709).

Consequentemente, coloca-se o desafio para que a própria gestão de recursos hídricos ofereça respostas ante os conflitos de uma época de incertezas, ampliadas devido à crise climática e às condiçóes socioeconômicas, desafios que exigirão a aplicação de novas práticas de gestão. Nesse contexto, apresenta-se a 
gestão adaptativa "defendida como uma extensão da GIRH para lidar com estes desafios, pois visa aumentar a capacidade de adaptação das bacias hidrográficas com base em uma compreensão profunda dos principais fatores que determinam sua vulnerabilidade." (PAHL-WOSTL et al., 2005, p.4).

Os conflitos e as tensóes em torno da escassez e da qualidade da água fizeram surgir, primeiramente nas instâncias da ONU, os conceitos da Gestão Adaptativa (GA) alicerçados em teorias de resiliência e envolvidos com a gestáo de incertezas por meio da experimentação formal e da aprendizagem baseada em processos sociais (ENGLE et al., 2011).

A combinação de GIRH e GA permite uma conjugação de teoria e prática, a reunir diferentes instituiçóes e mecanismos voltados para o incremento de eficácia, a participação e a democratização do público em geral e das partes interessadas, a ampliação do conhecimento por diferentes formas e a promoção de flexibilidade e adaptabilidade. Trata-se de uma transição sociotécnica, compreendida como a mudança de um regime sociotécnico para outro. Para García-Soler, Moss e Papasozomenou (2018, p.97), esse regime alude a "uma configuração particular de elementos materiais e sociais que, ao longo do tempo, se auto fortalece e, consequentemente, é difícil de mudar.”. Esquematicamente, os princípios da GIRH e da GA e as possíveis tensôes de sua associação são demonstrados na Fig. 1.

Figura 1 - Esquema simplificado de Gestão Integrada de Recursos Hídricos (GIRH) Gestão Adaptativa (GA) e das tensōes potenciais de sua associação

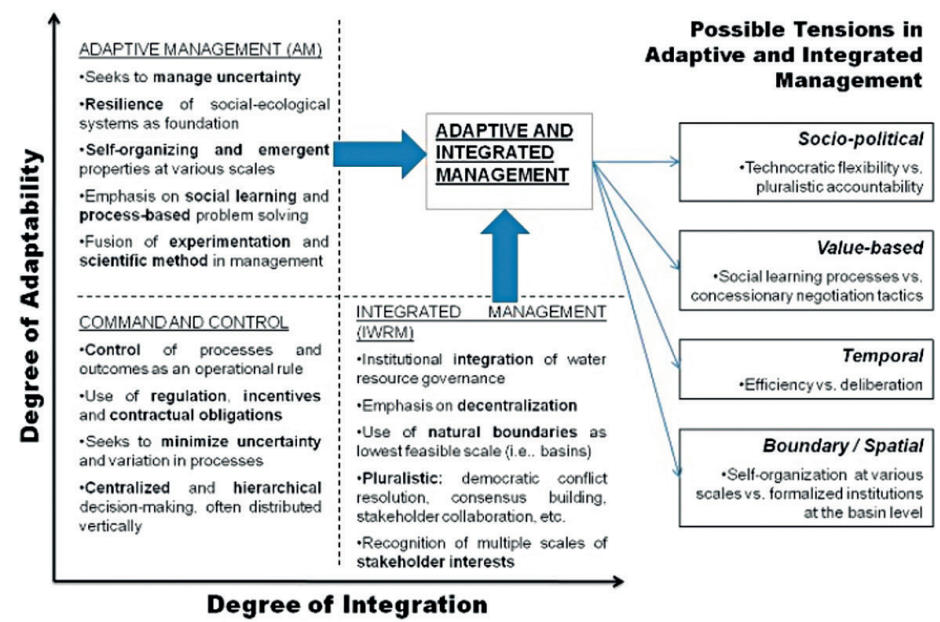

Fonte: Engle et al. (2011, p.5). 
$\mathrm{Na}$ Fig. 1, os eixos representam os graus de integração e de adaptabilidade e, além disso, as características predominantemente atribuídas a cada processo, ambos a representar transições sociotécnicas de um modelo de gestão precedente. O modelo de comando e controle centralizado e hierárquico, predominante até os anos 1980 está representado no quadrante inferior esquerdo. No quadrante superior direito situa-se a evolução da GIRH e da GA para uma gestão adaptativa e integrada, com o apontamento de possíveis tensôes observadas nessa governança convergente, sob perspectivas sociopolíticas, de bases de valores, de temporalidades e de limites espaciais.

Observa-se que a tendência evolutiva para a GIRH aponta à direção da agregação dos princípios adaptativos, em que a governança é uma das dimensóes importantes para o desenvolvimento da capacidade adaptativa (LOCKWOOD et al., 2015 apud JACOBI; SULAIMAN, 2017, p.56), que "inclui foco em eficácia, eficiência, legitimidade e participação.” (GUPTA; PAHL-WOSTL; ZONDERVAN, 2013, p.577).

O enfrentamento de incertezas - que compreendem os desastres naturais e a crise climática - possui relaçáo direta com o desenvolvimento da capacidade adaptativa e o incremento evolutivo da governança hídrica. Para Jacobi e Sulaiman (2017), os sucessos adaptativos impactam decisivamente um sistema socioecológico na mobilização de recursos para a melhor resposta e o consequente posicionamento em situação superior nesse enfrentamento, enquanto os insucessos conduzem a soluçóes que resultam em permanência ou agravamento de vulnerabilidades.

Em direção à gestão adaptativa e integrada, um ambiente de governança das águas institucionalizado conforme a GIRH foi colocado à prova ante a situação fática de enfrentamento de uma escassez hídrica, que afetou sobremaneira toda a Macrometrópole Paulista. Para melhor compreender o ambiente de análise, apresenta-se uma breve descrição sobre a origem, a concepção, o arcabouço legal e a estrutura da GIRH do estado de São Paulo.

\section{A governança de recursos hídricos de São Paulo}

No período entre 1972 e 1992, o sistema sociotécnico ambiental brasileiro recebe inegável inspiração das iniciativas dos países do Norte global quanto ao estabelecimento de políticas ambientais para o controle e a redução da degradação de recursos naturais, especialmente das águas (GRANZIERA, 2000; AITH; ROTHBARTH, 2015). 
A Constituição Federal de 1988 (BRASIL, 1988) consagrou perspectiva abrangente para o disciplinamento legal de todos os usos das águas brasileiras, ao dispor sobre a obrigação da União de instituir um sistema de governança de recursos hídricos ${ }^{2}$, dispositivo regulamentado pela Lei Federal no 9.433, de 8 de janeiro de 1997 (BRASIL, 1997), que institui a Política Nacional de Recursos Hídricos e cria o Sistema Nacional de Gerenciamento de Recursos Hídricos (SINGREH).

Segundo Machado (2015, p.295), essa lei reconheceu expressamente o "direito de acesso à água", reforçando "o fundamento da água como um bem de domínio público, (...) um recurso natural limitado e dotado de valor econômico." (AITH; ROTHBARTH, 2015, p.171). Além disso, estabelece que a gestão descentralizada e participativa dos múltiplos usos das águas deve ser: democrática e com o Poder Público, os usuários e a sociedade civil; e, organizada por bacia hidrográfica como unidade de planejamento, gestão e implementação do SINGREH. Em sintonia com as diretrizes da GIRH, instrumentos como os Planos de Recursos Hídricos, o sistema de informaçóes e outros, mostram que

O Brasil evoluiu no processo quanto à Gestão de Recursos Hídricos, pois ao implantar a Lei de Recursos Hídricos deu o primeiro passo instituindo o mecanismo amplo de gestão das águas, criou os instrumentos como outorga, cobrança e enquadramento dos rios (metas de qualidade da água), estabelecendo as condiçóes de contorno para as cidades quanto à contaminação dos rios. (TUCCI, 2008, p.169).

A bacia hidrográfica assume protagonismo como unidade de planejamento e gerenciamento de recursos hídricos, coerentes com a concepção e as boas práticas da GIRH da "gestão das águas delegada a comitês e conselhos de recursos hídricos, com a participação, além da União e dos Estados, de Municípios, usuários de recursos hídricos e da sociedade civil.” (GRANZIERA, 2000, p.72).

Antecipando-se à lei federal, quatro estados haviam criado as respectivas políticas de governança de recursos hídricos em escala regional a partir dos preceitos constitucionais. A primeira foi em São Paulo ${ }^{3}$, onde a Constituição Estadual de 1989 dedicou uma seção (arts. 205 a 213) para tratar da governança dos recursos hídricos, manifestamente na direção da gestão democrática das águas no território paulista (SÃO PAULO, 1989).

\footnotetext{
2 “Art. 21. Compete à União: (...) XIX - instituir sistema nacional de gerenciamento de recursos hídricos e definir critérios de outorga de direitos de seu uso;" (BRASIL, 1988).

3 Após São Paulo, Ceará (Lei no 11.996/1992), Minas Gerais (Lei no 11.504/1994) e Rio Grande do Sul (Lei $\left.\mathrm{n}^{\circ} 10.350 / 1994\right)$.
} 
Tais diretrizes orientaram a Lei no 7.663, de 30 de dezembro de 1991, que estabelece a Política Estadual de Recursos Hídricos, executada por meio do Sistema Integrado de Gerenciamento de Recursos Hídricos (SIGRH), com o suporte financeiro do Fundo Estadual de Recursos Hídricos (FEHIDRO) para a execução de programas, projetos, serviços e obras para a gestão, recuperação e proteção das bacias hidrográficas, previstos no Plano Estadual de Recursos Hídricos e nos Planos de Bacia Hidrográfica. A legislação paulista apoia-se em princípios basilares de "gerenciamento descentralizado, participativo e integrado", reconhecendo a água como um bem público, cuja gestão deve assegurar "padrôes de quantidade e qualidade satisfatórios aos cidadãos e para as futuras geraçôes" e com adoção da "bacia hidrográfica como unidade físico-territorial de planejamento e gerenciamento." (SÃO PAULO, 1991).

O estado de Sáo Paulo foi dividido em 22 Unidades Hidrográficas de Gerenciamento de Recursos Hídricos (UGRHI) ${ }^{4}$, delimitadas por regióes hidrográficas que compartilham um curso d'água principal estadual, mostradas na Fig. 2.

Figura 2 - Unidades de Gerenciamento de Recursos Hídricos (UGRHI) e Regiôes Hidrográficas do estado de São Paulo

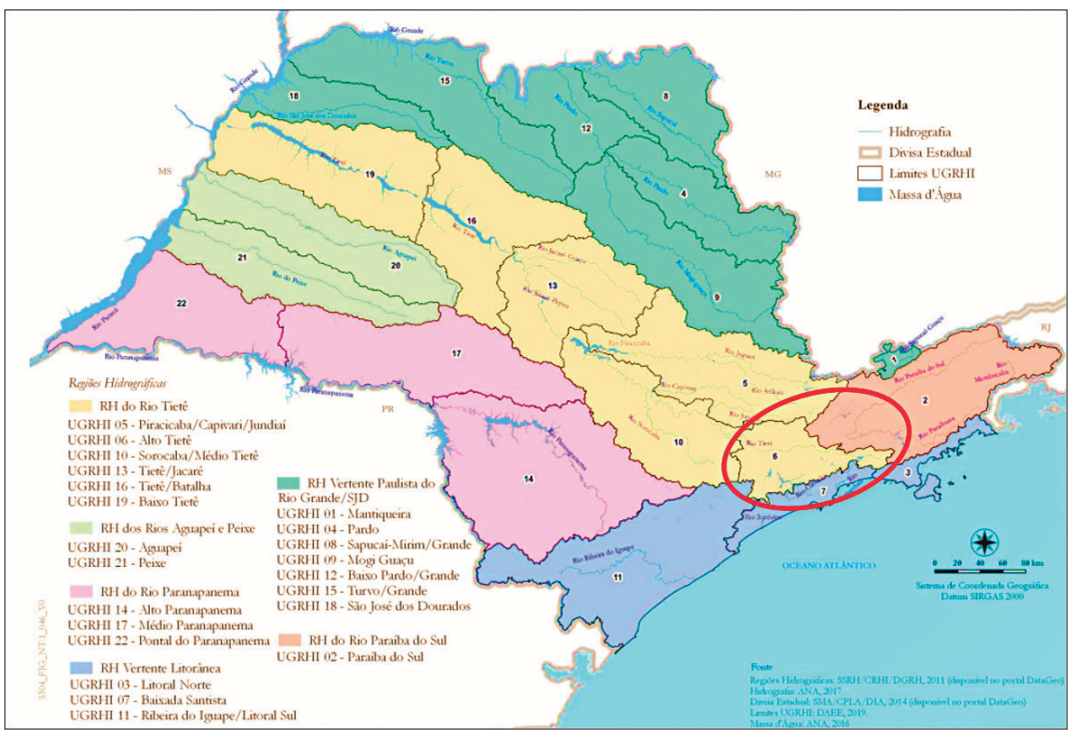

Fonte: SIGRH $(2020$, p.3)

\footnotetext{
4 Conforme a Lei n ${ }^{\circ}$ 9.034, de 27 de dezembro de 1994 (SÃO PAULO, 1994), posteriormente revogada pela Lei $\mathrm{n}^{\circ} 16.337$, de 14 de dezembro de 2016, que revalidou a divisão do estado nessas 22 UGRHIs.

5 Em destaque, está a UGRHI-6, área de abrangência do Comitê da Bacia Hidrográfica do Alto Tietê.
} 
Instâncias deliberativas, técnicas e financeiras com atuação interdependente compóem a estrutura do SIGRH. As deliberativas são o Conselho Estadual de Recursos Hídricos $(\mathrm{CRH})^{6}$ e os Comitês de Bacia Hidrográfica $(\mathrm{CBH})$. O CRH delibera sobre: formulação, implantação e acompanhamento da Política Estadual de Recursos Hídricos; PERH; relatórios de situação; diretrizes orçamentárias; e, propostas de $\mathrm{CBH}$ s para enquadramento de corpos d'água, programas de investimentos e fixação de valores da cobrança.

A cada UGRHI corresponde um $\mathrm{CBH}$, com exceção às UGRHI 20 (Aguapeí) e 21 (Peixe), agrupadas sob o CBH Aguapeí-Peixe. Criados pela Lei no 7.663/1991, os CBHs têm caráter deliberativo e competências, em sua área geográfica, para: elaborar o PBH e os relatórios de situação; propor valores para cobrança do uso dos recursos hídricos; aplicar recursos financeiros; enquadrar corpos d'água; e conciliar disputas entre usuários.

A estrutura de governança conta também com (i) Comitê Coordenador do Plano Estadual de Recursos Hídricos (CORHI), composto apenas por órgãos do estado para apoio ao CRH; (ii) Conselho de Orientaçáo do Fundo Estadual de Recursos Hídricos (COFEHIDRO), que supervisiona a gestão do FEHIDRO; (iii) Câmaras Técnicas, constituídas no CRH e nos $\mathrm{CBH}$ s para assessorar quanto a temas específicos de planejamento e gestão dos recursos hídricos; e (iv) Agências de Bacia para exercer a secretaria executiva do $\mathrm{CBH}$; elaborar e revisar o PBH; elaborar os relatórios anuais da situação dos recursos hídricos; gerenciar os recursos financeiros do FEHIDRO da bacia hidrográfica; operacionalizar a cobrança pelo uso da água; e realizar estudos e projetos de interesse do $\mathrm{CBH}^{7}$.

No início do século XXI, Gomes e Barbieri (2004, p.12) esperavam que a composição tripartite, composta pelos segmentos do Estado, dos Municípios e da Sociedade Civil em todos os seus colegiados de gestão, desvincularia a subordinação direta às decisóes do Estado, então "convidado a abandonar o seu papel autoritário e paternalista, detentor de todo o poder decisório" e a compartilhar a gestão com prefeituras, usuários e representaçóes civis.

$\mathrm{Na}$ mesma época, o arcabouço institucionalizado da governança da água em São Paulo sinalizava uma expectativa positiva para a evolução da cultura de planejamento de recursos hídricos e de superação de obstáculos em direção a uma gestão compartilhada.

\footnotetext{
6 Criado pelo Decreto n ${ }^{\circ} 27.576$ de 11 de novembro de 1987.

7 A implantação de Agência de Bacia ocorreu em apenas três CBHs (Piracicaba, Capivari e Jundiaí; Sorocaba e Médio Tietê; e Alto Tietê), pois dependem da viabilidade econômica da sua fonte de receita que provém, essencialmente, da dotação de até dez por cento dos recursos arrecadados com a cobrança pelo uso dos recursos hídricos da respectiva UGRHI, prevista no art. $8^{\circ}$ da Lei estadual $n^{\circ} 10.020 / 1998$.
} 
Os impactos das práticas participativas na gestão de recursos hídricos, apesar de controversos, apontam, a partir da manifestaçáo do coletivo, para uma nova cidadania, que institui o cidadão como criador de direitos para abrir novos espaços de participação sociopolítica, aspectos que configuram barreiras que precisam ser superadas para multiplicar iniciativas de gestão compartilhada. (JACOBI; FRACALANZA, 2005, p.42).

Desse modo, a governança hídrica instalada mostrava-se com potencial para o incremento e o maior protagonismo da participação da coletividade em um ambiente sociopolítico de diálogo com a tecnocracia, sinalizando, sob esse aspecto, para um processo evolutivo de convergência com a GA e na direção da gestão compartilhada das águas.

\section{A gestão da escassez hídrica e o Comitê da Bacia do Alto Tietê}

A evolução para a gestão integrada e adaptativa deve compreender que uma crise hídrica é, primordialmente, uma crise de governança que não será resolvida por meio da despolitização e dos processos de engenharia e gestão tecnocrática, pois é profundamente política em sua essência, desde a escala global até a local (CONCA, 2005; CASTRO, 2007; GUPTA; PAHL-WOSTL; ZONDERVAN, 2013). Para Pahl-Wostl et al. (2005), a participação das partes interessadas é um elemento-chave da gestão adaptativa e da transição para regimes de gestão mais adaptáveis.

No período de abril de 2013 e até o final de 2015, uma seca bastante severa com precipitaçóes muito abaixo da média histórica até então observada, impactou significativamente a afluência de águas aos reservatórios dos sistemas de abastecimento da MMP, comprometendo o abastecimento de água de milhóes de pessoas na regiâo. Para diversos autores (ALIANÇA PELA ÁGUA, 2015; JACOBI; CIBIM; LEÃO, 2015; FRACALANZA; FREIRE, 2016), o enfrentamento desse evento climático extremo evidenciou problemas de gestão e planejamento, pois as respostas institucionais foram insuficientes e a gravidade da situação foi subestimada por questóes políticas e eleitorais. Embora a redução da quantidade de água disponível estivesse associada à redução das vazóes afluentes aos reservatórios devido a uma estiagem prolongada, ela foi "o reflexo da falta de planejamento estratégico que afeta o sistema de abastecimento de água da Região nos últimos dez anos." (CÔRTES et al., 2015).

A Bacia Hidrográfica do Alto Tietê (UGRHI-6), que delimita a área de atuação do CBH-AT, ocupa lugar central e irradiador na Macrometrópole 
Paulista, e apresenta grande aderência espacial com a delimitação legal definida para a Região Metropolitana de São Paulo (RMSP), abrigando mais de 21 milhōes de habitantes.

A UGHRI-6 concentra um grande e adensado contingente populacional e uma forte atividade econômica, ao passo que apresenta insuficiente disponibilidade hídrica interna, utilizando-se de águas transferidas a partir de UGRHIs limítrofes para suprir perto da metade de sua demanda para abastecimento público urbano. A escassez hídrica em boa parte do Sudeste brasileiro impactou a regularização dos mananciais e provocou tensôes internas e externas nas UGRHIs e respectivos Comitês da Macrometrópole Paulista. Foi, talvez, a melhor oportunidade para colocar a GIRH de São Paulo à prova, inclusive quanto à possível trajetória rumo à gestáo integrada e adaptativa.

Um dos elementos fundamentais nessa direção é a transparência mediante acesso à informação pública e disponível de forma facilitada, isto é, "os indivíduos impactados pelas açóes de terceiros têm o direito de saber a qual risco eles estão expostos e o potencial de impacto sobre a sua saúde." (EMPINOTTI et al., 2017, p.149).

Durante largo período da crise, houve dificuldades para a disponibilização ou a interpretação de dados corretos e confiáveis, principalmente devido ao intuito do estado de estabelecer completo controle da narrativa mantendo-se como detentor pleno de todas as informaçóes. Um exemplo notório consta na divulgação pública, em sítio eletrônico da $\mathrm{SABESP}^{8}$, dos níveis e percentuais de armazenamento de água nos reservatórios do Sistema Cantareira - o manancial mais afetado pela escassez. Embora volumes de água abaixo do nível zero já estivessem sendo captados emergencialmente desde 16 de maio de 2014, os níveis e percentuais eram apresentados como positivos, conduzindo a interpretaçóes equivocadas para minimizar a crise publicamente. A informação foi retificada somente no segundo semestre de 2015, após o Ministério Público do Estado de São Paulo ter movido uma ação civil pública contra a empresa com base na Lei de Acesso à Informação (Lei no 12.527/2011), que a obrigou a divulgar os índices reais (negativos) de armazenamento do Sistema Cantareira.

$\mathrm{Na}$ disputa pelo uso da água que se instalou a partir de janeiro de 2014, quando o cenário de esvaziamento do Sistema Cantareira mostrava-se praticamente irreversível a ponto de exigir açóes de restriçáo, esperava-se que os Comitês de Bacia Hidrográfica exercessem uma de suas principais atribuiçóes: a

\footnotetext{
8 A SABESP (Companhia de Saneamento Básico do Estado de São Paulo) é empresa estadual de economia mista, prestadora de serviços de abastecimento de água e operadora dos mananciais que abastecem 21 milhões de habitantes da Região Metropolitana de São Paulo.
} 
mediação e a arbitragem de conflitos relacionados aos usos dos recursos hídricos. O desempenho dessa função pelos colegiados é intrinsecamente dependente da existência de dois fatores. Um deles é ser reconhecido pelo meio sociopolítico externo quanto à sua legitimidade, tanto como um espaço de diálogo para a administração de conflitos quanto para a obtenção de um consenso político. $\mathrm{O}$ segundo, a presença de um processo participativo interno de discussão e decisão capaz de abrigar os diversos atores, formalmente representados ou circunstancialmente envolvidos e interessados na disputa.

Previamente, no entanto, para observar a atuação do CBH-AT durante o evento da escassez hídrica cumpre entender o seu status quo estrutural e técnico-administrativo com relação à governança da água em conformidade com a GIRH naquele período.

Nos biênios 2009-2011 e 2011-2013, o CBH-AT sofreu um esvaziamento na participação em todos os seus segmentos devido a diversas disputas internas, notadamente na sociedade civil. Após debruçar-se sobre o acervo documental do CBH-AT desde sua fundação em 1994 até 2016, Anjos (2017, p.120-121) constatou que determinados temas eram apresentados de tal forma que os representantes em Plenário mostravam ter "a visão do Comitê como um local para resolução de problemas pontuais, provavelmente pela falta de diretrizes prioritárias, característico de um sistema novo em formação de sua base identitária.”

A degradação da atuação do CBH-AT levou ao adiamento por cinco meses das eleiçóes para o biênio 2013-2015. Em junho de 2013, uma ampla reformulação do estatuto ${ }^{9}$ alterou substancialmente a composiçáo da representação da sociedade civil no plenário, com ampliação do número das entidades representantes dos usuários de recursos hídricos e do mercado imobiliário, e a consequente redução da representação de ONGs e entidades não vinculadas aos setores produtivos. Como exemplo, as entidades centrais e regionais da Federação e do Centro das Indústrias do Estado de São Paulo (FIESP/CIESP) saltaram de duas cadeiras na gestão 2011-2013 para seis em um total de 18 vagas nas gestóes subsequentes (CBH-AT, 2021a).

Essa nova estrutura na composição e nos instrumentos de participação afastou do CBH-AT um conjunto de atores sociais relevantes em face à complexidade da RMSP, tais como as entidades e os movimentos interessados nos conflitos entre o uso do solo e os recursos ambientais, um tema determinante para a qualidade e a quantidade das águas na UGRHI-6.

9 Deliberação CBH-AT no 02 , de 04 de junho de 2013, que aprovou reforma do Estatuto do CBH-AT. 
O CBH-AT também não contava com um apoio administrativo e técnico próprio, pois sua Agência de Bacia, embora criada em 2003, ainda não dispunha de fonte de subsistência financeira para cobrir despesas com custeio e pessoal, visto que a cobrança pelo uso dos recursos hídricos na UGRHI 06 iniciou-se somente em abril de 2014.

Ao eclodir a crise hídrica, o CBH-AT encontrava-se, de certo modo, fragilizado quanto à sua independência estrutural e à sua representação participativa, pois estava em meio ao processo de consolidação da reorganização e, ainda bastante dependente do aparato tecnoburocrático estatal para o exercício de suas atribuiçōes.

Apesar desse contexto interno, em fevereiro de 2014, ocorre a primeira (e única) manifestação aprovada pelo plenário do $\mathrm{CBH}$-AT diretamente relacionada à crise, a Moção CBH-AT n ${ }^{\circ} 01$ de 05 de fevereiro de 2014, que recomendou açóes: (i) à ANA e ao $\mathrm{DAEE}^{10}$, para uma gestão rigorosa e permanente das águas armazenadas; (ii) aos Municípios, para redução de consumo e fiscalização de desperdícios; (iii) às entidades da sociedade civil atuantes no Comitê, para adesão ao esforço de redução do consumo de água; e, (iv) ao estado de São Paulo, para investir na ampliaçáo da capacidade de produção de água, na redução de perdas e na gestão de demanda (CBH-AT, 2021b).

O CBH-AT, naquele momento, adotou mais duas iniciativas: (i) a criação em caráter permanente da Câmara Técnica de Monitoramento Hidrológico, que, entretanto, foi formalizada somente em 31 de março de 2015; e (ii) a formação do Grupo de Trabalho de Gestão de Demanda. Este último elaborou um conjunto de 32 açóes para fomentar a redução de consumo e o uso racional da água na área de atuação do CBH-AT, consolidadas na Deliberação CBH-AT no 17 , de 12 de dezembro de 2014, e propondo iniciativas - às três esferas de governo, a outras instituiçóes e ao próprio CBH-AT - desde a redução de tributos para aparelhos economizadores de água até a elaboração de um plano de contingência. Ao mesmo tempo, movimentos exógenos ao $\mathrm{CBH}$-AT começaram a colocar à prova seu papel como instrumento descentralizado de GIRH.

Por meio da Resolução Conjunta ANA/DAEE no120/2014, também em fevereiro de 2014, foi instituído o Grupo Técnico de Assessoramento para Gestão do Sistema Cantareira (GTAG-Cantareira) com o objetivo de acompanhar a evolução do armazenamento, aperfeiçoar o uso dos recursos hídricos disponíveis, recomendar medidas de restrição e minimizar impactos aos usuários, tanto

\footnotetext{
${ }^{10}$ ANA é a Agência Nacional de Águas e DAEE é o Departamento de Águas e Energia Elétrica, órgãos gestores respectivamente da União e do Estado de São Paulo para concessão e controle da outorga pelo uso das águas do Sistema Cantareira, composto por rios estaduais e federais.
} 
àqueles da RMSP, beneficiários da transposição das águas de jurisdição federal e estadual situadas na Bacia Piracicaba, Capivari e Jundiaí, assim como aos situados a jusante do Sistema (ANA; DAEE, 2014). O grupo foi composto por um representante de cada órgão outorgante, a federal ANA e o estadual DAEE; um da empresa outorgada, a SABESP; um do Comitê das Bacias Hidrográficas dos Rios Piracicaba, Capivari e Jundiaí (CBH-PCJ); e um do CBH-AT.

Entretanto, a manifesta intenção de estabelecer-se um vínculo orgânico do GTAG-Cantareira com os Comitês mostrou-se, na prática, fracassada. Os representantes indicados pelos Comitês foram seus respectivos secretários executivos, que eram funcionários de carreira do DAEE nomeados para cargos na administração estadual e, naturalmente, somavam-se aos demais indicados pelas instituiçóes estatais, afastando-se do exercício de um papel de controle social ou participativo em nome dos Comitês (FRACALANZA, 2017). Nenhuma discussão sobre a gestão da escassez no âmbito do GTAG-Cantareira foi trazida ao plenário de ambos os Comitês por seus representantes nesse grupo (CBH-AT, 2021a).

O levantamento dos assuntos relevantes debatidos pelo CBH-AT no período em análise (ANJOS, 2017) mostra que nas seis plenárias de 2014, o tema da escassez hídrica foi pautado três vezes, a primeira para apresentação das açôes empreendidas pela SABESP, e as subsequentes para apresentaçóes dos impactos e açôes em curso nos cinco municípios com autarquias ou empresas próprias para a prestação de serviços de saneamento. Destaca-se a 5a Plenária, de 03 de outubro de 2014, em que foi pautada a discussão da participação dos Comitês de Bacias no GTAG-Cantareira, com as exposiçóes do diretor-presidente da ANA e dos representantes do DAEE, da SABESP e do CBH-AT. A operação do volume de água ainda disponível no Sistema Cantareira havia se transformado em objeto de fortes controvérsias entre as esferas federal e estadual, inclusive com a retirada voluntária da ANA no GTAG-Cantareira (AGÊNCIA..., 2014). Nessa reunião, esperava-se que o CBH-AT pudesse debater e mediar o conflito para a melhor gestão das águas, já bastante escassas. Contudo as expectativas foram frustradas, pois, com exceção de apenas um, os demais 17 representantes do estado estiveram ausentes por determinação governamental. Com o comparecimento de apenas uma das partes em litígio, a ANA, exauriu-se mais uma possibilidade de ação descentralizada e participativa por meio do Comitê, em que prevaleceu a vontade do governo estadual para a interdição do debate político e a manutenção da narrativa e das iniciativas sob seu controle (CBH-AT, 2021a).

A exclusão da participação do CBH-AT na discussão desse assunto prioritário, sob qualquer aspecto quantitativo ou qualitativo, consumou-se com a 
edição do Decreto Estadual no 61.111, de 03 de fevereiro de $2015^{11}$, que instituiu, sob a coordenação da Secretaria de Saneamento e Recursos Hídricos, o Comitê de Crise Hídrica (CCH) no âmbito da RMSP, para "intercâmbio de informaçóes e o planejamento de açóes conjuntas em face do correlato fenômeno climático que atinge parte do território estadual." (SÃO PAULO, 2015). Para compor o $\mathrm{CCH}$, nomearam-se oito órgãos estaduais, três universidades estaduais, um órgão federal, sete prefeitos municipais, oito entidades da sociedade civil e nenhum Comitê de Bacia. Das representantes da sociedade civil apenas a FIESP fazia parte do CBH-AT.

O CCH reuniu-se em 13 de fevereiro de 2015 - auge da crise - e definiu apenas uma medida: a elaboração de um plano de contingência no prazo de 30 dias, que, porém, foi concluído em setembro de 2015. O CBH-AT não foi sequer consultado durante a elaboração desse plano, tampouco o recebeu oficialmente.

Em 2015, na pauta das oito plenárias realizadas (ANJOS, 2017) houve três apresentaçóes por representantes da SABESP, uma da Secretaria Estadual de Saneamento e Recursos Hídricos (SSRH), e uma da Companhia Ambiental do Estado de São Paulo (CETESB), todas com o objetivo de informar sobre as obras e as ações de operação dos reservatórios e de redução de consumo. Embora houvesse questionamentos - alguns contundentes - por representantes de municípios e de entidades da sociedade civil não usuárias de recursos hídricos, náo houve espaços para as manifestaçóes de outras organizaçóes e movimentos da sociedade civil, por exemplo, a Aliança pela Água e o Coletivo de Luta pela Água. Em síntese, o estado prosseguiu no controle da narrativa informando ao $\mathrm{CBH}-\mathrm{AT}$ suas principais iniciativas e providências, sem levar em consideração qualquer alteração de rumo nas soluções tecnocráticas adotadas e tergiversando nas polêmicas, como a redução de pressão na rede de distribuição de água que causava desigual distribuição do abastecimento, especialmente nas áreas periféricas da RMSP (MILLINGTON, 2018).

As justificativas oficiais não esclareceram o conflito entre discurso e prática ante a negação do desabastecimento provocado pela "redução de pressão controlada”, um conjunto de manobras hidráulicas da SABESP nas redes de distribuição adotado para reduzir o consumo e as perdas de água invisíveis no sistema de tubulaçóes. Essas manobras fizeram o papel de um racionamento pla-

\footnotetext{
${ }^{11}$ O Decreto $\mathrm{n}^{\mathrm{a}} 61.111$ foi publicado no Diário Oficial do Estado (DOE) em 4 de fevereiro de 2015 e republicado no DOE em 5 de fevereiro de 2015 para inclusão na sua composição das Secretarias Estaduais de Agricultura e Abastecimento e de Energia, e do Prefeito de Campinas. Também foi alterado pelo Decreto Estadual no 61.135 , de 25 de fevereiro de 2015, tão somente para incluir a Confederação Nacional do Turismo.
} 
nejado, porém não divulgado à população, isto é, os gestores estaduais optaram por não adotar um plano de rodízio "democrático" entre setores de diferentes camadas sociais. Sem qualquer intercessão por meio do CBH-AT, evidenciava-se o conflito social pela água.

A falta de água em quantidade e qualidade, resultante da crise hídrica no município de São Paulo, levou a um acirramento do conflito social pelo uso da água disponível. Esse conflito foi ainda mais exacerbado pela falta de posicionamento claro sobre as medidas de gerenciamento da água adotadas pela Sabesp, tanto no que se refere à redução da pressáo da água e adoção de um racionamento, quanto a um sistema transparente de rodízio de água. (SINISGALLI et al., 2018, p.82).

O permanente e absoluto controle em mãos do governo estadual sobre as narrativas e medidas adotadas para enfrentamento da crise, dificultou sobremaneira o envolvimento da sociedade e, por consequência, propositadamente excluiu qualquer participação dos Comitês de Bacia, em que se fazem representar com direito a voz e voto representantes de municípios e da sociedade civil.

Quando observamos a atuação do governo do estado de São Paulo diante da crise hídrica, vemos que a posição tomada é absolutamente contrária ao que se espera para obter-se uma boa governança da água. Com um discurso absolutamente técnico e centralizador, o estado de São Paulo afasta qualquer integração com a população, podando o envolvimento da sociedade na discussão, tanto da causa da crise, como também das possíveis soluçóes para o enfrentamento do problema. (JACOBI; CIBIM; LEÃO, 2015, p.36).

As atas de reunióes desse período (CBH-AT, 2021a) mostram que, de certo modo, as entidades hegemônicas no segmento social do CBH-AT omitiram-se dos debates, reduzindo a capacidade da sociedade civil quanto à articulação interna e à conjugação junto aos movimentos externos para a construção de narrativas de contestação ao estado no âmbito do Comitê. Essas entidades representantes de setores econômicos, tão logo perceberam a dimensão da escassez, estabeleceram diálogos bilaterais com a governança tecnocrática do estado, visando manter as condiçóes para a reprodução do capital mediante concessão de benefícios ou garantias para a sua continuidade durante a crise. 


\section{Legados da crise para o Comitê da Bacia do Alto Tietê}

Durante a escassez hídrica, as decisóes estiveram centralizadas em apenas um dos atores da governança da água: o estado. Não houve consultas ou debates junto aos CBHs da Macrometrópole Paulista e os questionamentos públicos foram colocados à margem (TORRES; CÔRTES; JACOBI, 2020). Apesar da incontestável ruptura da GIRH nesse evento crítico, os Comitês, de alguma forma, movimentaram-se para uma possível evolução à governança integrada e adaptativa. Apontam-se aqui três aspectos: representatividade, transparência e autonomia.

Primeiramente, corrobora-se a afirmação de Jacobi, Cibim e Leão (2015, p. 35-36), que entendem o arranjo jurídico-normativo paulista como um elemento limitador para o envolvimento da comunidade nas atividades dos $\mathrm{CBH}$, pois "coloca em primeiro plano a importância do corpo técnico-científico e do conhecimento produzido por ele nas relaçóes de força no interior dos espaços decisórios da bacia." Os autores afirmam ainda que o CBH-AT "apresenta um quadro bastante complexo, principalmente no que diz respeito à pouca efetividade das decisôes e da representação da sociedade civil.”.

A partir dos impactos socioambientais da crise hídrica de 2013-2015, emergiu a discussão sobre a composição da representação nos colegiados paulistas. Definida por lei estadual que precedeu à federal, a composição dos $\mathrm{CBH}$ paulistas obedece a uma proporcionalidade tripartite que tem sido questionada judicialmente. A partir de demandas de movimentos da sociedade civil por uma maior amplitude de transparência e informação para a sociedade sobre a gestão da crise, o Ministério Público do Estado de São Paulo promoveu iniciativas judiciais para obrigar os $\mathrm{CBHs}$ a adotarem proporcionalidade de representação semelhante à vigente na esfera federal ${ }^{12}$, que limita a "representação dos poderes executivos da União, Estados, Distrito Federal e Municípios à metade do total de seus membros." (BRASIL, 1997).

Uma dessas iniciativas resultou em sentença expedida pelo Tribunal de Justiça do Estado de São Paulo, que exigiu alteração da composição do plenário do $\mathrm{CBH}-\mathrm{PCJ}$ de forma a adequá-lo às disposiçóes da lei federal ${ }^{13}$. Em abril de 2019, o estatuto foi alterado com uma nova composição de trinta e três membros, distribuídos em oito vagas para o estado, oito para Municípios, nove para organizaçóes civis e oito para associaçóes de usuários de recursos hídricos

\footnotetext{
12 Estabelecida no art. 39, $\S 1^{\circ}$ da Lei Federal no $9.433 / 1997$.

${ }^{13}$ Processo no $^{0}$ 1000437-05.2018.8.26.0451.
} 
(CBH-PCJ, 2019). Os poderes executivos de estado e municípios tornaram-se minoritários ante a soma da sociedade civil e dos usuários no plenário desse Comitê. No âmbito do CBH-AT há, também, um procedimento jurídico com idêntica finalidade ${ }^{14}$.

Independentemente dos efeitos de decisôes judiciais sobre a composição equitativa, na eleição para a representação da sociedade civil do CBH-AT para o biênio 2021-2023, o sistema FIESP-CIESP teve sua presença reduzida para três vagas titulares em favor da inédita presença de associaçóes representativas de usuários para abastecimento público (CBH-AT, 2021c). Em paralelo, articula-se um movimento em favor de uma alteração estatutária na composição, para abrir espaço à maior pluralidade de organizaçóes e entidades, favorecendo maior protagonismo e presença dos atores sociais da Bacia Hidrográfica do Alto Tietê.

No quesito transparência, a disponibilidade e o acesso público às informaçóes e aos documentos do CBH-AT foram substancialmente incrementados por uma reorganização - iniciada em 2019 e concluída em 2020 - de banco de dados, sítio eletrônico e mídia social ${ }^{15}$. Milz. Braga e Jacobi (2020) avaliaram a disponibilização pública de atas de plenário dos Comités inseridos na MMP, constatando que, a partir de 2015, as informaçóes do CBH-AT são disponibilizadas de forma bastante acessível em tempo relativamente curto.

Um terceiro aspecto que aponta para uma evolução na governança do CBH-AT está no fortalecimento da Fundação Agência da Bacia Hidrográfica do Alto Tietê (FABHAT). Após mais de uma década de existência dependente de pequenas doaçóes de alguns municípios, a partir de meados de 2015 a FABHAT obteve condiçóes legais e burocráticas para custear suas despesas com a parcela de $10 \%$ da arrecadação com a cobrança pelo uso dos recursos hídricos na UGRHI-6. De 2014 a 2020, o montante arrecadado alcançou pouco mais de R \$ 240 milhóes que correspondem a cerca de R \$ 24 milhóes para custeio nesse período ${ }^{16}$.

Em 2017, com a indicação pelo CBH-AT - por meio de processo seletivo público - de um novo presidente para a FABHAT, iniciou-se a reorganização da Agência para exercer as atribuiçôes legais de: (i) prestação de apoio administrativo e técnico ao CBH-AT; (ii) elaboração de estudos e planos sobre as águas

\footnotetext{
${ }^{14}$ Inquérito Civil n ${ }^{\circ}$ MP 14.1090.000000/2016-2 em que o representado é o CBH Alto Tietê.

${ }^{15}$ A mídia social do CBH-AT contava, em março de 2021, com mais de 1.400 seguidores.

${ }^{16}$ Informação apresentada em reunião plenária de 10 de fevereiro de 2021, que aprovou a Deliberação CBH-AT $\mathrm{n}^{\mathrm{a}}$ 116, sobre o Plano de Aplicação dos Recursos da Cobrança pelo Uso da Água de 2021. Disponível em: https:// comiteat.sp.gov.br/wp-content/uploads/2021/02/Plano-de-Aplica\%C3\%A7\%C3\%A3o-Cobran\%C3\%A7a-2021Apresenta\%C3\%A7\%C3\%A3o-realizada-na-1\%C2\%AA-Plen\%C3\%A1ria-Extraordin\%C3\%A1ria-do-CBHAT-de-2021.pdf. Acesso em: 20 mar. 2021.
} 
da UGRHI 6; (iii) cobrança pelo uso de recursos hídricos e gestão dos valores arrecadados; (iv) atuação como órgão técnico das APRMs; e, (v) gerenciamento dos recursos do FEHIDRO vinculados ao CBH-AT. O Plano de Trabalho da FABHAT para 2021, aprovado por seu Conselho Deliberativo (FABHAT, 2020), apresenta um conjunto de açôes para o aperfeiçoamento e a consolidação de suas funçôes.

Em comparação com o período da crise hídrica é possível depreender que o CBH-AT, em 2021, possui uma tendência a maior pluralidade em sua composição; possui um patamar superior de transparência e fidedignidade de informaçóes; e está mais bem aparelhado e mais independente do aparato do estado para o exercício de suas atribuiçóes.

\section{Considerações finais}

Concebida como um GIRH, a governança hídrica paulista foi colocada à prova com a escassez crítica de 2013-2015. Evidenciou-se a sua fratura conceitual, pois durante todo o processo de gestão da crise desse período houve sistemática ação do estado contrária à participação das instâncias colegiadas descentralizadas dos Comitês de Bacia, como ficou evidente nos episódios do GTAG-Cantareira e do Comitê da Crise Hídrica. Também há avaliaçôes críticas quanto à ausência de transparência das informaçóes. Portanto, foram prejudicadas as iniciativas democráticas de governança que poderiam ter sido pactuadas nesses colegiados como açóes administrativas consensuais. Ao contrário, os Comitês foram alijados das "discussóes e processos decisórios para enfrentamento da crise” (TORRES; CÔRTES; JACOBI, 2020, p.72).

Assim, por um lado, as oportunidades para o protagonismo dos Comitês envolvidos foram bloqueadas ou desprezadas pelo aparato político. Por outro lado, os colegiados cujas UGRHIs foram mais afetadas pela crise não desempenharam o seu papel de protagonistas na interlocução perante os atores políticos e da sociedade.

Em síntese, tais aspectos revelam um padrão de governança brasileiro que corresponde a uma estrutura concebida para atender aos preceitos e práticas de GIRH em ambiente democrático, descentralizado, participativo e integrado que, contudo, enfrenta obstáculos para o seu pleno exercício, notadamente no quesito da participação, quando se observa o contexto da escassez hídrica de 2013-2015.

A análise sobre a atuação do CBH-AT no decurso da crise mostrou a sua fragilidade institucional enquanto meio de expressão social, acompanhada de uma absoluta ausência de protagonismo, sequer em plano secundário. Embora 
concebido como o espaço regional da GIRH, evidenciou-se o rompimento dos alardeados pilares básicos da governança hídrica paulista: descentralização, participação e integração. De fato, o CBH-AT não teve "nenhuma possibilidade de participar da gestáo da crise de abastecimento ou mesmo acompanhar suas principais decisôes." (FRACALANZA, 2017, p.177).

A ausência de uma representação articulada e forte da sociedade civil nos Comitês colaborou para a débil atuação. Contudo, o ajuste implantado na composição do CBH-PCJ, que poderá repercutir para o $\mathrm{CBH}-\mathrm{AT}$ e os demais Comitês paulistas, tende a abrir espaço para maior diversidade de organizaçóes e entidades no plenário e nos instrumentos de participação dispostos em sua estrutura, que atualmente, quando postos à prova, pendem a favor do Poder Público e dificultam um maior protagonismo dos atores sociais da bacia hidrográfica na governança da água.

Um possível estudo conectado a uma agenda de pesquisa sobre o grau de coerência da integração proposta pela GIRH, poderia se dedicar à análise da ampliação da participação da sociedade civil na composição dos Comitês, quanto à responsabilidade compartilhada na tomada de decisóes e no controle social sobre a governança das águas, especialmente ante uma nova situação de escassez hídrica.

As incertezas associadas à crise climática potencializam o retorno de eventos semelhantes ou até mais drásticos em comparação com o período 2013-2015. O Sistema Cantareira voltou ao nível de alerta durante alguns meses em 2018, 2019 e 2020. Outros mananciais que atendem a demanda de abastecimento urbano da RMSP também poderão sofrer redução de vazóes afluentes aos seus reservatórios com maior frequência.

É incerto também em que medida a governança hídrica por meio do CBH-AT poderá influir em processos de antecipaçáo, debate e negociação de conflitos. Entretanto, visto que é de sua competência prevenir e promover açóes para evitar ou reduzir efeitos de estiagens, uma medida convergente para a GA é antecipar-se a uma escassez vindoura. A elaboraçáo de um plano de contingência é uma medida antecipatória capaz de preparar a sociedade e estabelecer uma prévia pactuação da alocação da água. Não se trata de um plano impositivo ou aleatório, concebido pela tecnoburocracia de cima para baixo, mas, sim, um plano elaborado, debatido e validado horizontalmente pelos segmentos e entidades presentes no Comitê, e também por outros protagonistas e segmentos sociais que não estão representados na composição do CBH-AT, e que, contudo, possivelmente sofrerão os impactos de uma nova crise hídrica. 
Para alcançar um status de representação orgânica e reconhecida pela sociedade, o CBH-AT e - por extensão - os demais comitês paulistas, necessitam aprimorar a governança hídrica para um rumo convergente para a GA. Por exemplo, ao adotar um Plano de Bacia Hidrográfica que considere as incertezas e os riscos associados à crise climática, com foco na gestão resiliente e que privilegie a essencialidade da água, primeiramente para os usos voltados à preservaçáo da vida em todas as suas formas e, secundariamente, para a função econômica de geração de valor agregado.

Depreende-se que há um longo caminho a ser percorrido para alcançar o desejado padrão de uma gestão integrada e adaptativa de recursos hídricos na Macrometrópole Paulista, capaz de mitigar efeitos das mudanças climáticas com respostas que incorporem os princípios adaptativos à governança hídrica, com ênfase em resiliência, aprendizagem social, legitimidade e participação.

\section{Agradecimento}

Este artigo resulta de atividades do projeto temático, em andamento, "Governança ambiental da Macrometrópole Paulista, face às variabilidades climáticas”, financiado pela Fundação de Amparo à Pesquisa do Estado de São Paulo (FAPESP) - Processo FAPESP no 15/03804-9 - e vinculado ao Programa FAPESP de Pesquisa sobre Mudanças Climáticas Globais.

\section{REFERÊNCIAS}

AGÊNCIA afirma que governo de SP não revela gravidade de crise hídrica. G1, São Paulo, 24/set/2014. Disponível em: http://g1.globo.com/sao-paulo/noticia/2014/09/ agencia-nacional-de-aguas-afirma-que-governo-de-sp-nao-revela-gravidade-de-crisehidrica-populacao.html. Acesso em: 20 mar. 2021.

AITH, F.M.A.; ROTHBARTH, R. O estatuto jurídico das águas no Brasil. Estudos Avançados, São Paulo, v.29, n.84, p. 163-177, 2015. Disponível em: https:/www. scielo.br/j/ea/a/rzjGTQ7yBVbJ3RSkKHb4L7n/?format=pdf. Acesso em: 20 mar. 2021.

ALIANÇA PELA ÁGUA. Chamado à ação sobre a crise hídrica: por um plano de emergência para o estado de SP. Sáo Paulo, 2015. Disponível em: https://issuu.com/ saladecrise/docs/3_chamado_alian_a/3. Acesso em: 20 mar. 2021.

ALVAREZ, C. O que significa a água começar a ser cotizada no mercado de futuros de Wall Street?. El País Brasil, 08 dez. 2020. Disponível em: https://brasil.elpais.com/ 
economia/2020-12-09/o-que-significa-a-agua-comecar-a-ser-cotizada-no-mercadode-futuros-de-wall-street.html. Acesso em: 20 mar. 2021.

ANA; DAEE. Resoluçáo Conjunta ANA/DAEE No 120 de 10 de fevereiro de 2014. Dispóe sobre a criação do grupo técnico de assessoramento para a gestão do Sistema Cantareira no atual período de crise de escassez de chuvas e afluências. São Paulo, 2014. Disponível em: http://www.daee.sp.gov.br/site/gestao-do-sistemacantareira/. Acesso em: 25 nov. 2020.

ANJOS, L. A. P. Análise da gestão dos corpos hídricos urbanos da bacia hidrográfica do Alto Tietê. 2017. 224f. Dissertação (Mestrado em Ambiente, Saúde e Sustentabilidade) - Faculdade de Saúde Pública, Universidade de São Paulo, São Paulo, 2017. Disponível em: doi:10.11606/D.6.2017.tde-01092017-143227. Acesso em: 25 nov. 2020.

ASAMBLEA GENERAL DE LAS NACIONES UNIDAS. Resolución aprobada por la Asamblea General el 28 de julio de 2010: 64/292: El derecho humano al água e el saneamiento. 2010. Disponível em: https://undocs.org/es/\%20A/RES/64/292. Acesso em: 30 abr. 2020.

BARBOSA, M. C.; ALAM, K.; MUSHTAQ, S. Water policy implementation in the state of São Paulo, Brazil: Key challenges and opportunities. Environmental Science and Policy, New York, v. 60, p. 11-18, 2016.

BENSON, D.; GAIN, A. K.; ROUILLARD, J. J. Water governance in a comparative perspective: From IWRM to a "nexus" approach? Water Alternatives, Montpellier, v. 8, n. 1, p. 756-773, 2015.

BRASIL. Lei n. 9.433, de 8 de janeiro de 1997. Institui a Política Nacional de Recursos Hídricos, cria o Sistema Nacional de Gerenciamento de Recursos Hídricos, regulamenta o inciso XIX do art. 21 da Constituição Federal, e altera o art. $1^{\circ}$ da Lei no 8.001, de 13 de março de 1990, que modificou a Lei no 7.990, de 28 de dezembro de 1989. Diário Oficial da Uniáo, Brasília, 9 jan. 1997. Seção 1, p. 470.

BRASIL. Constituição (1988). Constituição da República Federativa do Brasil. Promulgada em 5 de outubro de 1988. Brasília: Senado Federal, 1988.

BRENNER, N. Espaços da Urbanizaçáo: o urbano a partir da teoria crítica. Rio de Janeiro: Letra Capital, 2018.

CASTRO, J. E. Water governance in the twentieth-first century. Ambiente \& Sociedade, São Paulo, v.10, n.2, p.97-118, 2007. Disponível em: https://www.scielo. br/j/asoc/a/gwKvL3Y8vGm685z797KdR9C/?lang=en\&format=pdf. Acesso em: 30 jan. 2021. 
COMITÊ DA BACIA HIDROGRÁFICA DO ALTO TIETÊ [CBH-AT]. Atas de reunióes plenárias 1994-2020. São Paulo, 2021a. Disponível em: https://comiteat. sp.gov.br/o-comite/atas/. Acesso em: 20 mar. 2021.

COMITÊ DA BACIA HIDROGRÁFICA DO ALTO TIETÊ [CBH-AT]. Deliberaçóes e Moçóes 1996-2021. São Paulo, 2021b. Disponível em: https:// comiteat.sp.gov.br/o-comite/deliberacoes-e-mocoes/. Acesso em: 20 mar. 2021.

COMITÊ DA BACIA HIDROGRÁFICA DO ALTO TIETÊ [CBH-AT]. Entidades do segmento Sociedade Civil no Comitê Alto Tietê, mandato 20212023, eleitas. São Paulo, 2021c. Disponível em: https://comiteat.sp.gov.br/o-comite/ processo-eleitoral-das-entidades-do-segmento-sociedade-civil/\#16149763448456219cfcd-e80f. Acesso em: 20 mar. 2021.

COMITÊS DAS BACIAS HIDROGRÁFICAS DOS RIOS PIRACICABA, CAPIVARI E JUNDIAÍ [CBH-PCJ]. Deliberaçáo dos Comitês PCJ no 316/2019. 25 abr. 2019. Piracicaba, 2020. Disponível em: https:/drive.google.com/file/d/1e7o wtAt5087oCyV0mTKxts7xyp1i6rKD/view. Acesso em: 17 jan. 2021.

CONCA, K. Governing Water: Contentious Transnational Policies and Global Institution Building. Minneapolis: MIT Press, 2005.

CÔRTES, P. L. et al. Crise de abastecimento de água em São Paulo e falta de planejamento estratégico. Estudos Avançados, São Paulo, v. 29, n. 84, p. 7-26, 2015. Disponível em: https://www.revistas.usp.br/eav/article/view/104933/103723. Acesso em: 20 mar. 2021.

EMPINOTTI, V.L.; JACOBI, P.R.; FRACALANZA, A.P.; BUJAK, N. Transparência e o acesso à informação na gestão dos recursos hídricos no Brasil. In: JACOBI, P.R.; FRACALANZA, A.P.; EMPINOTTI, V.L. (org.). Governança da água no contexto da escassez hídrica Sáo Paulo. São Paulo: IEE-USP,UFABC e GovAmb, 2017. p.147-161.

ENGLE, N. L.: JOHNS, O.R.; LEMOS, M.C.; NELSON, D.R. Integrated and adaptive management of water resources: Tensions, legacies, and the next best thing. Ecology and Society, Wolfville, v. 16, n. 1, art. 19, 2011.

FRACALANZA, A.P. Crise de governança da água: a recentralização na gestão da água no Estado de São Paulo (Brasil) In: JACOBI, P.R.; FRACALANZA, A.P.; EMPINOTTI, V.L.(org.). Governança da água no contexto da escassez hídrica Sáo Paulo. São Paulo: IEE-USP, UFABC e GovAmb. 2017. p.163-187.

FRACALANZA, A. P.; FREIRE, T. M. Crise da água na Região Metropolitana de São Paulo: injustiça ambiental, privatização e mercantilização de um bem comum. 
Geousp: Espaço e Tempo, São Paulo, v. 19, n. 3, p. 464-478, 2016. Disponível em: https://www.revistas.usp.br/geousp/article/view/103064/112861. Acesso em: 20 mar. 2021.

FUNDAÇÃO AGÊNCIA DA BACIA HIDROGRÁFICA DO ALTO TIETÊ [FABHAT]. Deliberaçáo do Conselho Deliberativo no 3, 27/out/2020. Aprova o Plano de Trabalho e a Proposta Orçamentária para o ano de 2021 da FABHAT. São Paulo, 2020. Disponível em: http://fabhat.org.br/wp-content/uploads/2020/12/ Deliberac\%CC\%A7a\%CC\%83o_Plano-de-Trabalho_2021.pdf. Acesso em: 20 mar. 2021.

GARCÍA-SOLER, N.; MOSS, T.; PAPASOZOMENOU, O. Rain and the city: Pathways to mainstreaming rainwater harvesting in Berlin. Geoforum, Oxford, v. 89, n. May 2017, p. 96-106, 2018.

GLOBAL WATER PARTNERSHIP [GWP]. About IWRM. 2018. Disponível em: https://www.gwp.org/en/gwp-SAS/ABOUT-GWP-SAS/WHY/About-IWRM. Acesso em: 02 jun. 2021.

GOMES, J. L.; BARBIERI, J. C. Gerenciamento de recursos hídricos no Brasil e no Estado de São Paulo: um novo modelo de política pública. Cadernos EBAPE.BR, São Paulo, v. 2, n. 3, p. 1-21, 2004. Disponível em: https://bibliotecadigital.fgv.br/ ojs/index.php/cadernosebape/article/view/4892/3626. Acesso em: 20 mar. 2021.

GRANZIERA, M. L. M. A cobrança pelo uso da água. Revista CEJ, Brasília, v. 4, n. 2, p. 71-74, 2000. Disponível em: https://revistacej.cjf.jus.br/cej/index.php/revcej/ article/view/362/510. Acesso em: 20 mar. 2021.

GUPTA, J.; PAHL-WOSTL, C.; ZONDERVAN, R. "Glocal” water governance: A multi-level challenge in the anthropocene. Current Opinion in Environmental Sustainability, Oxford, v. 5, n. 6, p. 573-580, 2013.

JACOBI, P.R.; FRACALANZA, A.P. Comitês de bacias hidrográficas no Brasil: Desafios de fortalecimento da gestão compartilhada e participativa. Desenvolvimento e Meio Ambiente, Curitiba, v. 11, p. 41-49, 2005. Disponível em: https://revistas. ufpr.br/made/article/view/7816/5523. Acesso em: 20 mar. 2021.

JACOBI, P.R.; CIBIM, J.; LEÃO, R.S. Crise hídrica na Macrometrópole Paulista e respostas da sociedade civil. Estudos Avançados, São Paulo, v. 29, n. 84, p. 27-42, 2015. Disponível em: https://www.revistas.usp.br/eav/article/view/104937/103727. Acesso em 20 mar. 2021.

JACOBI, P.R.; SINISGALLI, P.A.A.; MEDEIROS, Y.; ROMEIRO, A.R. Governança da água no Brasil: Dinâmica da política nacional e desafios para o futuro. In: JACOBI, 
P.R; SINISGALLI, P.A.A. Governança da água e políticas públicas na América Latina e Europa. São Paulo: Annablume, 2009. p. 49-82.

JACOBI, P.R., SULAIMAN, S.N. Governança Ambiental Urbana face às Mudanças Climáticas. In: JACOBI, P.R.; FRACALANZA, A.P.; EMPINOTTI, V.L. (org.). Governança da água no contexto da escassez hídrica Sáo Paulo. São Paulo: IEEUSP, UFABC e GovAmb, 2017. p. 51-64.

KRAMER, A.; PAHL-WOSTL, C. The global policy network behind integrated water resources management: Is it an effective norm diffusor? Ecology and Society, Wolfville, v. 19, n. 4, art. 11, p. 1-24, 2014.

MACHADO, P.A.L. Falta de água e soluçôes jurídicas. Revista Jurídica ESMP-SP, São Paulo, v.7, p.295-298, 2015. Disponível em: https://es.mpsp.mp.br/revista_ esmp/index.php/RJESMPSP/article/view/277. Acesso em: 20 mar. 2021.

MILLINGTON, N. Producing water scarcity in São Paulo, Brazil: The 2014-2015 water crisis and the binding politics of infrastructure. Political Geography, Oxford, v. 65, n. May 2017, p. 26-34, 2018.

MILZ, B.; BRAGA, D.; JACOBI, P.R. Evaluation of the transparency in the plenums minutes of the Water Basins in the Sao Paulo Macrometropolis (Brazil). In: LATINR 2020: Conferencia Latinoamericana sobre Uso de R en Investigación e Desarrollo, 3., 07 a 09 de outubro de 2020, Montevideo. Anales [...], Montevideo, 2020. Disponível em: https://macroamb-latin-r.netlify.app. Acesso em: 20 mar. 2021.

ORGANIZAÇÃO DAS NAÇŌES UNIDAS [ONU]. Declaraçáo de Dublin sobre Água e Desenvolvimento Sustentável. Dublin, 1992. Disponível em: http://www.abcmac.org.br/files/downloads/declaracao_de_dublin_sobre_agua_e_ desenvolvimento_sustentavel.pdf. Acesso em: 18 maio 2020.

PAHL-WOSTL, C.; DOWNING, T.; KABAT, P.; MAGNUSZEWSKI, P.; MEIGH, J.; SCHLUETER, M.; SENDZIMIR, J.; WERNERS, S. Transition to adaptive water management: The Project NeWater. Osnabrück: University of Osnabrück, Germany, 2005. (Working Paper 1. NeWater working paper series editor).

PAHL-WOSTL, C.; LEBEL. L.; KNIEPER, C.; NIKITINA, E. From applying panaceas to mastering complexity: Toward adaptive water governance in river basins. Environmental Science and Policy, New York, v. 23, p. 24-34, 2012.

PAHL-WOSTL, C.; VÖRÖSMARTY, C.; BHADURI, A.; BOGARDI, J.; ROCKSTRÖM, J.; ALCAMO, J. Towards a sustainable water future: Shaping the next decade of global water research. Current Opinion in Environmental Sustainability, Oxford, v. 5, n. 6, p. 708-714, 2013. 
SÃO PAULO. Decreto no 61.111, de 3 de fevereiro de 2015. Institui, sob a coordenação da Secretaria de Saneamento e Recursos Hídricos, o Comitê de Crise Hídrica no âmbito da Região Metropolitana de S. Paulo e dá providências correlatas. Diário Oficial do Estado, São Paulo, p.3, 4 fev. 2015.

SÃO PAUlO. Lei n. 9.034, de 27 de dezembro de 1994. Dispóe sobre o Plano Estadual de Recursos Hídricos - PERH, a ser implantado no período 1994 e 1995, em conformidade com a Lei 7663, de 30/12/1991, que instituiu normas de orientação à Política Estadual de Recursos Hídricos. Diário Oficial do Estado, São Paulo, p.3, 28 dez. 1994.

SÃO PAULO. Lei n. 7.663, de 30 de dezembro de 1991. Institui as normas de orientação à Política Estadual de Recursos Hídricos bem como ao Sistema Integrado de Gerenciamento de Recursos Hídricos. Diário Oficial do Estado, São Paulo, p.2, 31 dez. 1991.

SÃO PAUlO. Constituição (1989). Constituição do Estado de São Paulo; promulgada em 5 de outubro de 1989. São Paulo: Assembleia Legislativa do Estado de São Paulo, 1989.

SINISGALLI, P.A.A; FRACALANZA, A.P.; GIATTI, L.L.; TADEU, N.D. Consequências socioeconômicas da crise da água em São Paulo. In: BUCKERIDGE, M.; RIBEIRO, W.C. (org.). Livro branco da água: a crise hídrica na Região Metropolitana de São Paulo em 2013-2015: Origens, impactos e soluções. São Paulo: Instituto de Estudos Avançados, 2018.

SISTEMA INTEGRADO DE GERENCIAMENTO DE RECURSOS HÍDRICOS [SIGRH]. Plano Estadual de Recursos Hídricos: PERH 2020-2023. Sumário Executivo. São Paulo: SIGRH, 2020. Disponível em: http://www.sigrh.sp.gov.br// perh20202023. Acesso em: 20 mar. 2021.

TORRES, P.H.C.; CÔRTES, P.L.; JACOBI, P.R. Governing complexity and environmental justice: lessons from the water crisis in Metropolitan São Paulo (20132015). Desenvolvimento e Meio Ambiente, Curitiba, v.53, p. 61-77, jan./jun. 2020. Disponível em: https://revistas.ufpr.br/made/article/view/64673. Acesso em: 20 mar. 2021.

TUCCI, C. E. M. Águas Urbanas. Estudos Avançados, São Paulo, v. 22, n. 63, p. 97-112, 2008. Disponível em: https://www.revistas.usp.br/eav/article/view/10295/ 11943. Acesso em: 20 mar. 2021.

Recebido em: 30 de março de 2021

Aprovado em: 02 de julho de 2021 